\title{
The Need for Desiccant in Containers Exposed to Atmospheric Conditions for Long Periods of Time
}

Keith E. Mead

Prepared by

Sandia National Laboratories

Albuquerque, New Mexico $\mathbf{8 7 1 8 5}$ and Livermore, California 94550

for the United States Department of Energy

under Contract DE-AC04-76DP00789 
Issued by Sandia National Laboratories, operated for the United States Department of Energy by Sandia Corporation.

NOTICE: This report was prepared as an account of work sponsored by an agency of the United States Government. Neither the United States Government nor any agency thereof, nor any of their employees, nor any of their contractors, subcontractors, or their employees, makes any warranty, express or implied, or assumes any legal liability or responsibility for the accuracy, completeness, or usefulness of any information, apparatus, product, or process disclosed, or represents that its use would not infringe privately owned rights. Reference herein to any specific commercial product, process, or service by trade name, trademark, manufacturer, or otherwise, does not necessarily constitute or imply its endorsement, recommendation, or favoring by the United States Government, any agency thereof or any of their views and opinions expressed herein contractors or subcontractors. The views and opinions expressed herein do not necessarily state or reflect those of the United States Government, any agency thereof or any of their contractors or subcontractors.

Printed in the United States of America Available from

National Technical Information Service

U.S. Department of Commerce

5285 Port Royal Road

Springfield, VA 22161

NTIS price codes

Printed copy: A02

Microfiche copy: A01 
TABLE OF CONTENTS

$\begin{array}{lc}\text { ABSTRACT } & \text { PAGE NO. } \\ \text { INTRODUCTION } & 5-6 \\ \text { LEAK RATE TESTING } & 7 \\ \text { ELASTOMERIC O-RINGS } & 9 \\ \text { CONCLUSIONS AND RECOMMENDATIONS } & 21 \\ \text { REFERENCES } & 22 \\ \text { DISTRIBUTION } & 23 \\ \\ \text { LIST OF FIGURES }\end{array}$

$\begin{array}{lr}\text { Figure } 1 & 10 \\ \text { Figure 2 } & 11 \\ \text { Figure } 3 & 12 \\ \text { Figure 4 } & 14 \\ \text { Figure 5 } & 17 \\ \text { Figure 6 } & 20\end{array}$ 
THE NEED FOR DESICCANT IN CONTAINERS

EXPOSED TO ATMOSPHERIC CONDITIONS FOR LONG PERIODS OF TIME

K. E. Mead

Sandia National Laboratories

Albuquerque, New Mexico 87185

ABSTRACT

Current component and system designs are required to perform satisfactorily up to 25 years. A maximum leak rate of $1 \times 10^{-6} \mathrm{cc}$ (STP) helium/sec-atm is a frequent requirement for component containers. Calculations show that undesiccated component containers continuously exposed to $50 \%$ relative humidity at $20^{\circ} \mathrm{C}$ and having an internal free volume of less than $300 \mathrm{cc}$ and the above leak rate will allow the internal dew point to rise enough for potential liquid condensation in less than four years. For the same vapor pressure differential, the moisture permeation rate through one linear inch of silicone o-ring is 750 times as fast as moisture enters a welded container whose leak rate is $1 \times 10^{-6}$ CC(STP) helium/sec-atm. For ethylene propylene o-ring material this ratio is about 13 . These values correspond to the ratios of the quantities of desiccant required to maintain an acceptable dew point temperature when the moisture capacity of the free volume is not included.

Charts are provided for estimating the amount of desiccant required for helium leak tested containers and for containers sealed with elastomeric o-rings. 
INTRODUCTION

The designer of any container used for moisture sensitive apparatus and intended for long term storage must address the possible need for desiccation. Here, we relate the sensitivity of leak rate testing to the need for desiccating a container pointing out the significance of moisture permeation through elastomeric seals and demonstrating the approximate conditions under which desiccation is needed. We also compare the amount of desiccant required for welded and leak tested containers with containers sealed with elastomeric o-rings.

It is undesirable for liquid moisture to condense on moisture sensitive apparatus. To prevent condensation a sufficient amount of desiccant should be included in the design to maintain a dew point temperature well below the freezing point of water for the expected life of the design. A dew point of $-20^{\circ} \mathrm{C}$ is chosen to be the highest allowable for good engineering practice.

An initially dry container having a finite free volume of air can accommodate a small amount of water that represents saturation at a maximum allowable dew point temperature, arbitrarily $-20^{\circ} \mathrm{C}$, before any desiccation is required. If the container and its contents are initially dry and this small quantity of moisture does not permeate the container during its expected life no desiccation is needed. 
For the illustrations used in this paper it is arbitrarily assumed that a design may be subjected to a continuous $50 \%$ relative humidity at $20^{\circ} \mathrm{C}$ for its expected life. With the assumption of a constant external environment and a desiccated interior, the permeation rate of moisture will effectively be constant after an initial short period of moisture diffusion into the seal material. Under these conditions the amount of desiccant required becomes a linear function of time and the moisture permeation rate. 


\section{LEAK RATE TESTING}

Leak testing of sealed components to a leak rate sensitivity of $1 \times 10^{-6} \mathrm{cc}(\mathrm{STP})$ helium/sec-760 torr has been a common practice in the past and is still a frequently chosen leak rate sensitivity level. Current designs are now being required to perform satisfactorily up to 25 years. If this sersitivity of leak testing is used it must be assumed that a production container may leak at this rate. If it does, the equivalent leak rate of moisture will be approximately $6.2 \times 10^{-10}$ cc(STP) $\mathrm{H}_{2} \mathrm{O} / \mathrm{sec}$-torr. The leak rate of gases varies inversely as the square root of the ratio of their molecular weights. 1 Using ideal gas laws and assuming the exterior environment is a continuous $50 \%$ relative humidity at $20^{\circ} \mathrm{C}$, the curves of Figure $I$ indicate the interior dew point will rise to undesirable levels in only a few years if the interior volume is small.

Figure 2 indicates that a container having a free volume of 300 cubic centimeters and subjected to only $12 \frac{1}{2} \%$ relative humidity at $20^{\circ} \mathrm{C}$ will attain a dew point of $-20^{\circ} \mathrm{C}$ in only eight years.

Figure 3 indicates the effect of increasing the sensitivity of leak testing. The sensitivity values shown assume a helium pressure differential of one atmosphere, 760 torr. Decreasing the helium pressure differential during a leak test naturally decreases the leak rate sensitivity. Also, filling a container with potting compound may decrease its 


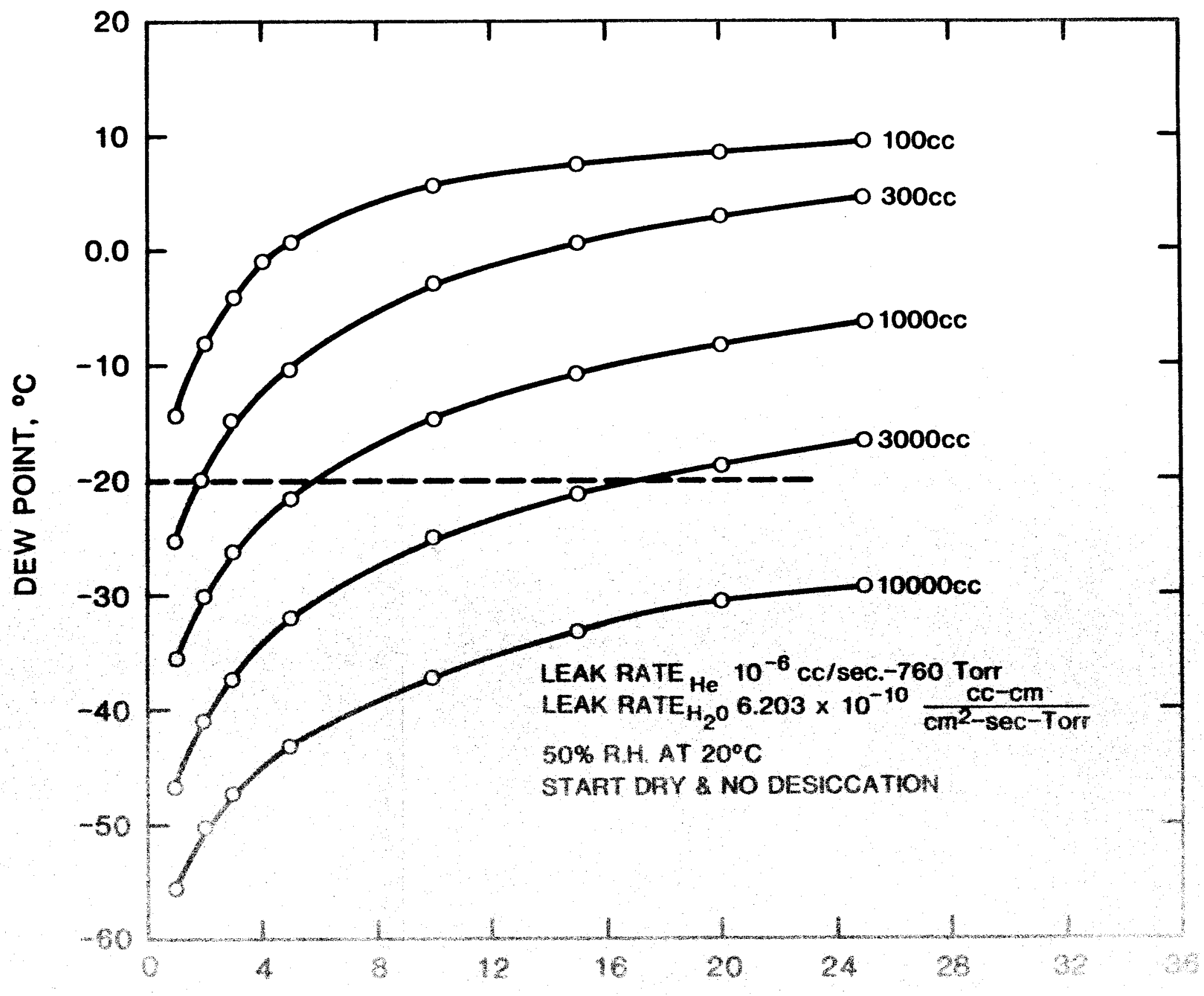




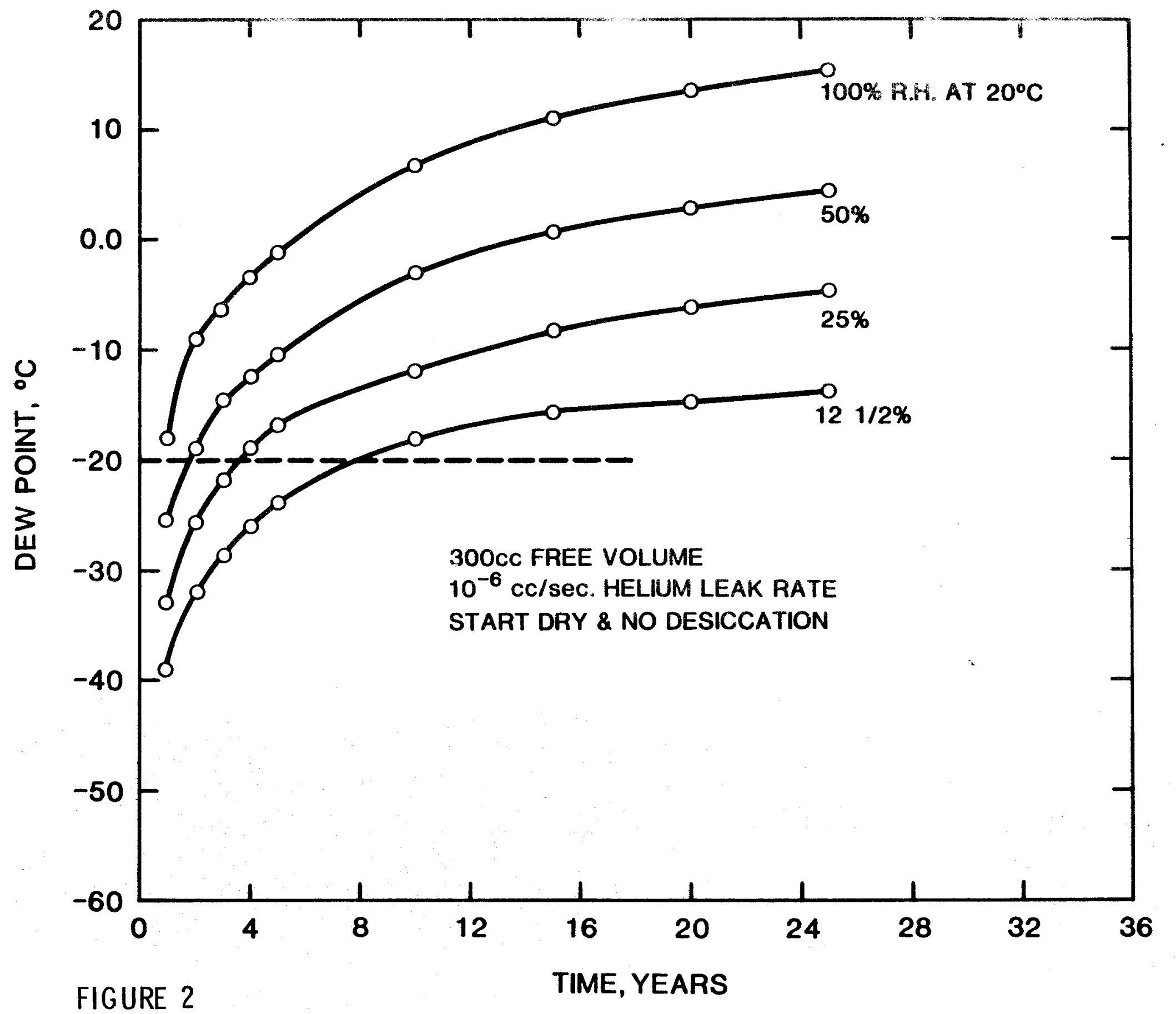




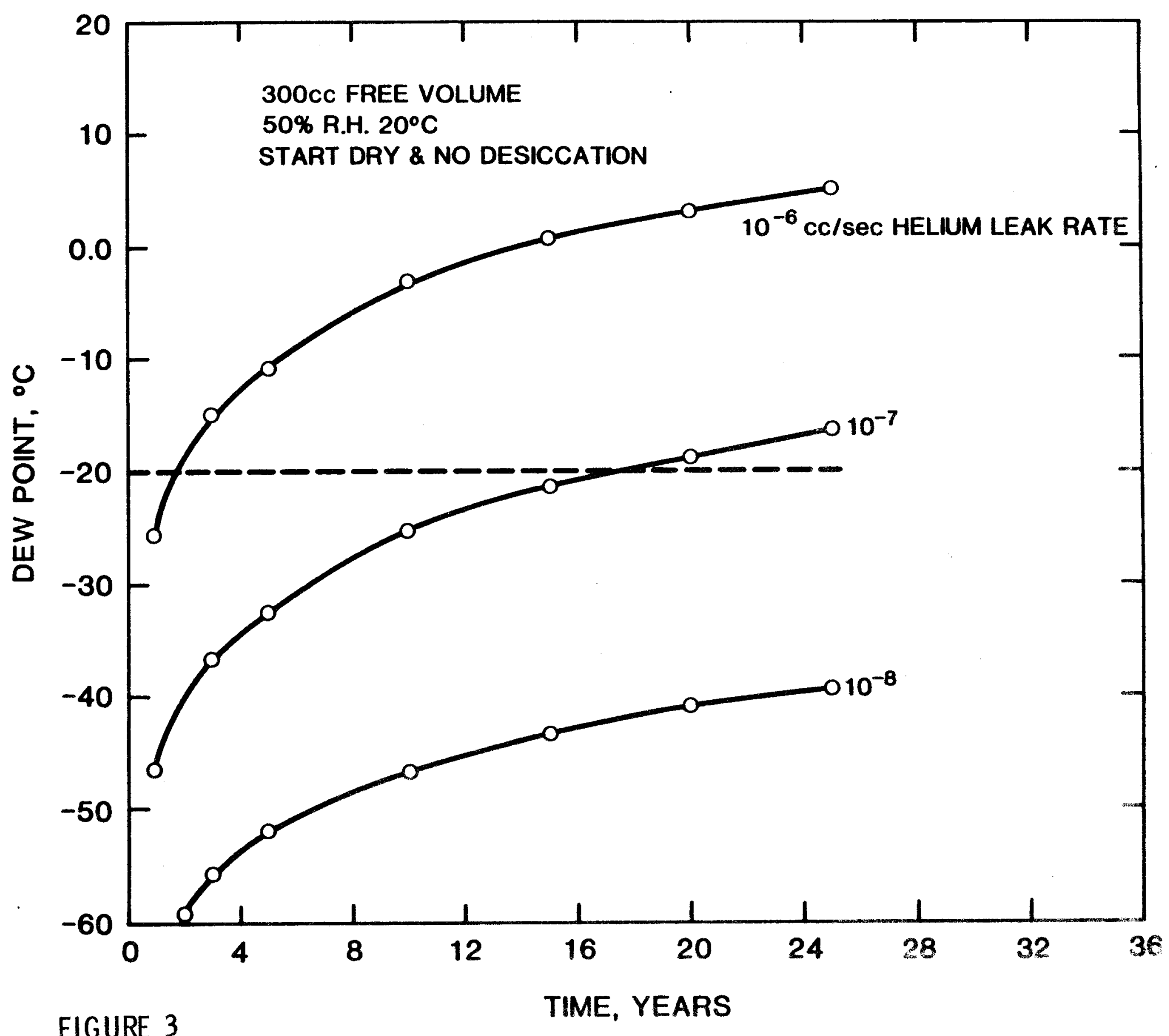


free volume drastically. These last two factors would increase the need for desiccant.

A frequent question regarding existing designs that have been stored and are approaching their originally expected life is, "How much longer can we expect satisfactory service?" The curves of Figures i-3 can be used to estimate dew point for extended storage.

Figure 4 provides a means of estimating the amount of $3 \AA$ molecular sieve desiccant required to maintain a dew point of $-20^{\circ} \mathrm{C}$ for two helium leak test sensitivities.

In developing the figures shown, the assumption that the containers were initially dry is optimistic. Hygroscopic materials such as printed circuit boards and potting compounds frequently carry moisture into a system. Unfortunately very few moisture - material isotherms are available for use in estimating the amount of moisture carried into an assembly.

Some hygroscopic materials such as foams and encapsulants might assume the dual function of desiccant. This is suggested by the small amount of desiccant required for containers leak tested to $1 \times 10^{-6} \mathrm{cc}$ (STP) He/sec-760 torr. For example, assume an environment of 508 relative humidity at $20^{\circ} \mathrm{C}, 8.77$ torr vapor pressure. The equivalent moisture leak of $6.2 \mathrm{x}$ $10^{-10} \mathrm{cc}\left(\right.$ STP)/sec-torr will result in $3.45 \times 10^{-3}$ grams of water gaining entry in 25 years. One gram of 3 angstrom desiccant can gather 0.18 grams of water at $20^{\circ} \mathrm{C}$ and still 





maintain a dew point of $-20^{\circ} \mathrm{C} .^{2}$ Thus less than 0.02 gram of desiccant would be required. This is a very small amount but is essential to prevent the possibility of liquid moisture condensation. Some of the materials used in the design for electrical or mechanical functions might easily absorb such small quantities of moisture if they were initially dry. 
ELASTOMERIC O-RINGS

The use of elastomeric o-rings to seal connector bodies and component containers or as the environmental seals of a weapon system is common practice. Silicone rubber O-rings are widely used but are known to permeate moisture much faster than most other seals. A single silicone rubber o-ring one inch in diameter will permeate moisture $2.6 \times 10^{3}$ times as fast as a container that has been helium leak rate tested to a sensitivity of $1 \times 10^{-6}$ Cc (STP) He/sec-760 torr. Thus any container exposed to nominal atmospheric conditions and sealed with silicone o-rings requires an internal desiccant if the dew point is to be controlled for more than a short time.

Moisture permeation constant (3) of commonly used o-ring materials are given in Table I below to indicate their relative permeation rates.

TABLE I

Material Permeation Constant $P \times 10^{7} \mathrm{cC}($ STP $)-\mathrm{cm} / \mathrm{cm}^{2}-$ sec-torr

Parker Silicone S-613-6 3.4

Parker Ethylenepropylene E-529-6 0.06

Viton 0.34

Parker Butyl B-318-7 0.015

Figure 5 relates a helium leak test to the moisture permeation that could be expected from a one inch diameter o-ring used to seal a container having an internal volume of 300 cubic centimeters. The curves clearly demonstrate the 


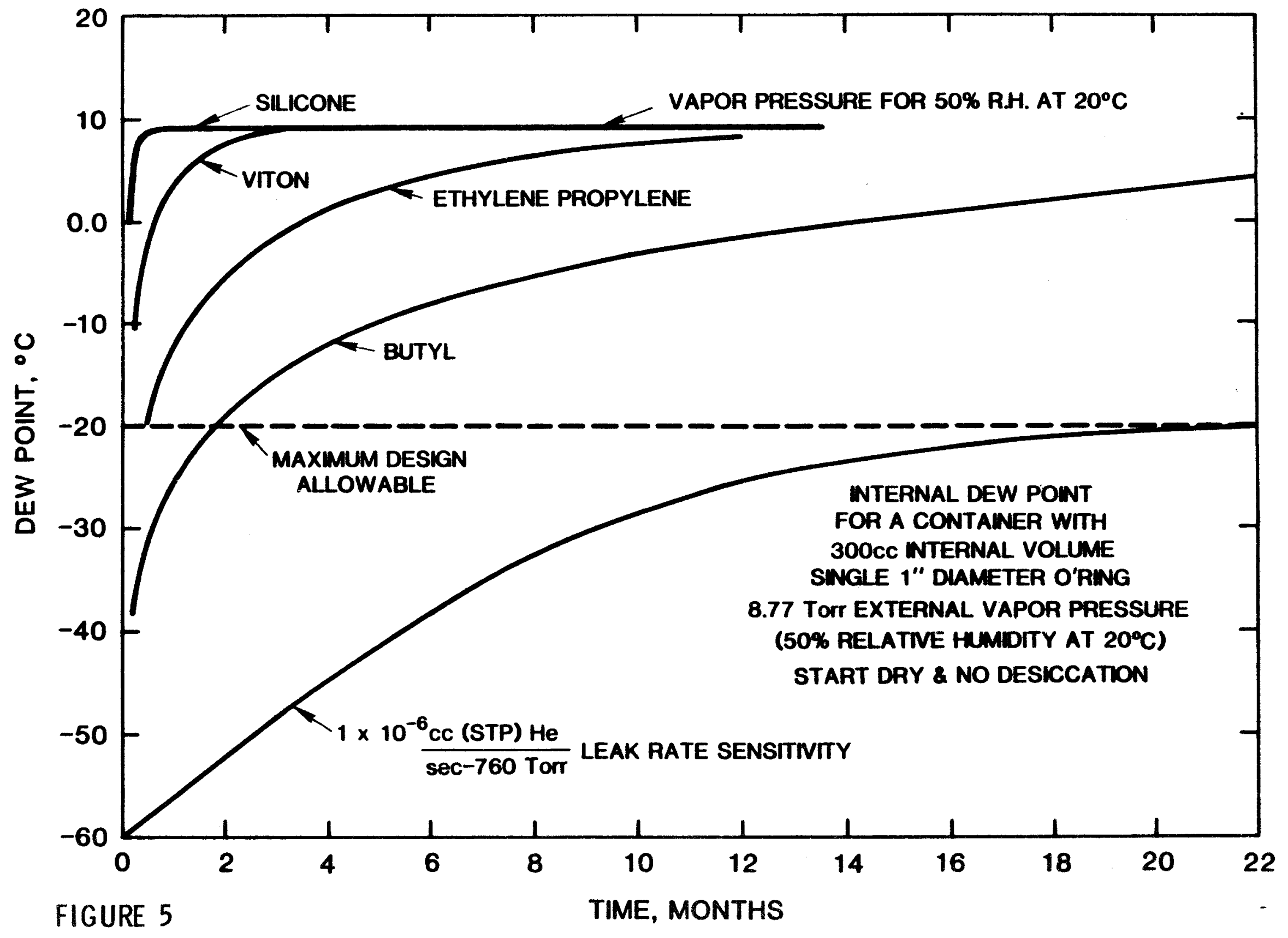


need for desiccant to control the internal dew point of containers sealed with elastomeric o-rings and exposed to nominal climatic conditions.

The permeation rate through an o-ring whose crosssection is large is the same as through one of small crosssection per linear inch. For all standard o-rings the ratio of the slot width to the depth is very nearly a constant and these dimensions are a function of the o-ring cross-section In application an o-ring is confined to the slot and approximately assumes the slot shape. For purposes of estimating permeation the frontal area is taken to be the product of the o-ring length and slot depth with the path length being the slot width.

A comparison of the amount of desiccant required for the commonly used seal materials is given in Table II for a one inch diameter o-ring. A continuous moisture pressure differential of 7.77 torr was assumed. This represents $50 \%$ relative humidity at $20^{\circ} \mathrm{C}$ outside while the desiccant holds the vapor pressure at one torr inside. 
TABLE II

\begin{tabular}{|c|c|c|}
\hline $\begin{array}{r}\mathrm{E} \\
\mathrm{Pe} \\
\mathrm{a} I \\
\text { o-rin }\end{array}$ & $\begin{array}{l}\text { Estimated } \\
\text { Moisture } \\
\text { ermeating } \\
1 \text { inch dia. } \\
\text { ng in } 25 \text { yrs. }\end{array}$ & $\begin{array}{c}\text { Amount of } 3 \AA \text { zeolite } \\
\text { Desiccant Required } \\
\text { for Max. dew point } \\
\text { Temperature of }-20^{\circ} \mathrm{C} \\
\text { for } 25 \text { yrs } \\
\end{array}$ \\
\hline Parker Silicone $5-613-6$ & 7.97 grams & 44.3 grams \\
\hline Parker Ethylenepropylene E-529-6 & 0.142 & 0.78 .9 \\
\hline Viton & 0.797 & 4.43 \\
\hline Parker Butyl B-318-7 & 0.035 & 0.204 \\
\hline $\begin{array}{l}\text { Helium leak rate sensitivity } \\
\text { of } 1 \times 10^{-6} \text { cc(STP) } \\
\mathrm{He} / \mathrm{sec}-760 \text { torr }\end{array}$ & 0.0034 & 0.02 \\
\hline
\end{tabular}

Figure 6 indicates the amount of $3 \AA$ molecular sieve desiccant required to maintain a dew point temperature of $-20^{\circ} \mathrm{C}$ for each linear inch of o-ring. Elastomeric seals quickly permeate the small amount of water necessary to raise the dew point to $-20^{\circ} \mathrm{C}$. As indicated in the figure a large volume does not preclude the need for desiccant for more than a short time when elastomeric o-rings are used for sealing.

The reader is reminded that these estimates assume the container was originally dry and contained no hygroscopic material. Desiccant requirements estimated from the charts should be increased by a factor sufficient to account for the hygroscopic nature of included materials and to provide an acceptable margin of safety. 


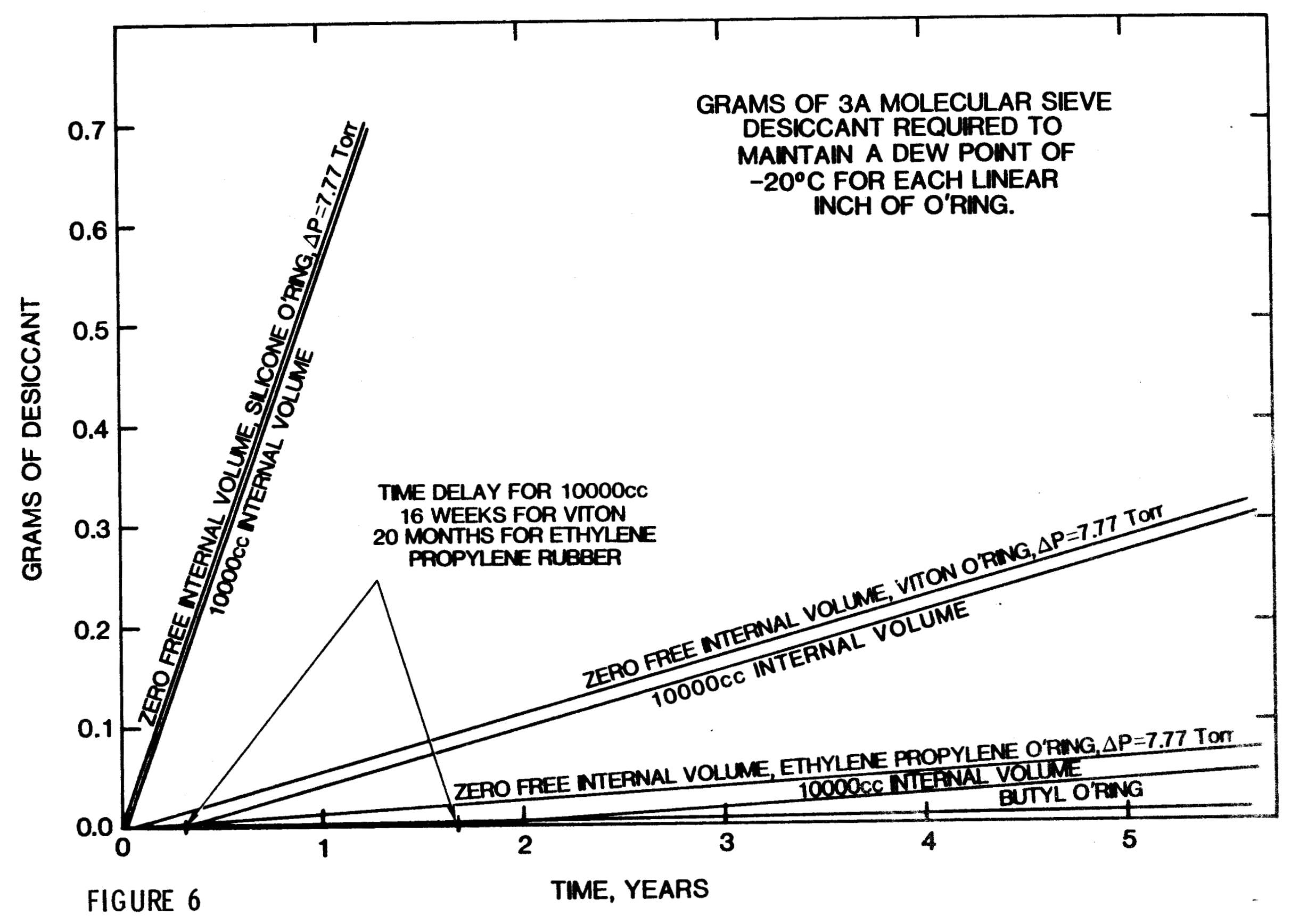


The data shown in the figures were generated using a computerized ideal gas law program. The inputs can be varied as necessary to include any range of input values not shown in the figures.

\section{CONCLUSIONS AND RECOMMENDATIONS}

Any undesiccated container with small internal volume and leak tested to a test sensitivity of $1 \times 10^{-6} \mathrm{cc}$ (STP) helium/sec-atm may permit the internal dew point temperature to rise to undesirable levels in less than four years. When tested at a leak rate sensitivity of $1 \times 10^{-8} \mathrm{cc}(\mathrm{STP}) / \mathrm{sec}$-atm a component container must have several cubic centimeters of free volume to maintain a dew point temperature below $-20^{\circ} \mathrm{C}$ for 20 years without desiccation.

A single one inch diameter o-ring as might be used with a small electrical connector body will permeate moisture much faster than the molecular flow of water through a leak of $1 \times 10^{-6} \mathrm{cc}$ (STP) helium/sec-atm.

Butyl rubber o-rings provide significantly improved environmental control as compared to silicone o-rings. The use of butyl o-rings are suggested when the high temperature characteristics of silicone are not required.

The amount of desiccant required to control moisture passing through o-rings is a linear function of its length. This is because the ratio of o-ring slot depth to width is constant. 


\section{REFERENCES}

1. Leakage Testing Handbook, J. William Marr, National Aeronautics and Space Administration CR-952, P. 49, dated April 1968.

2. Davison 3A Molecular Sieves, Davison Chemical Div. of W. R. Grace and Co.

3. Memorandum, J. P. Darginis, 8311, to Distribution, subject, Water and Helium Permeation, dated October $3 I$, 1968 . 
DISTRIBUTION :

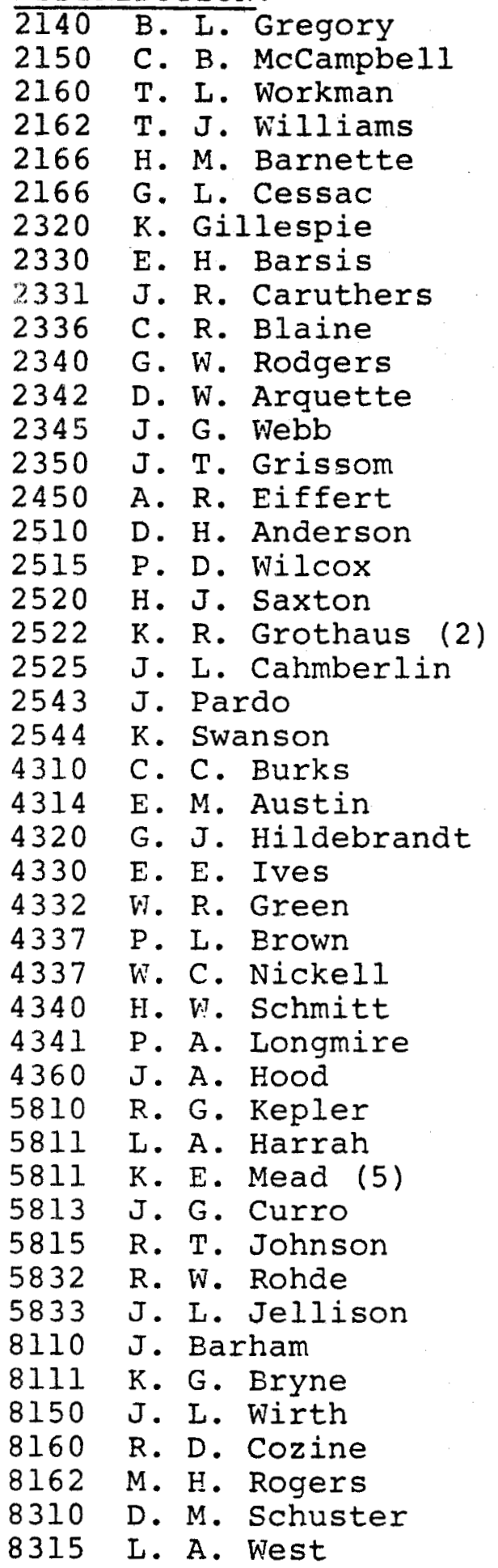

3141 L. H. Erickson (5)

3151 W. L. Garner (3)

For DOE/TIC

3154-4 C. Dahlin (25)

For DOE/TIC

8214 M. A. Pound 